\title{
A Study of Advanced English Teaching in the Setting of Multi-media and Internet
}

\author{
Xiulian Liu \\ Foreign Language School of Jianghan University, Wuhan, China \\ Liuxiulian1000@sina.com
}

\begin{abstract}
This paper aims to find out an effective way to improve Advanced English traditional teaching, which the cramming method tends to be employed by a teacher in class. It applies the constructivist learning theory to probe the advantages and challenges in the setting of multi-media and Internet. The research indicates that the new teaching mode in this setting can motivate students' interests enthusiasm, and cultivate their ability to explore in studying Advanced English course

Index Terms - the setting of multi-media and Internet Advanced English teaching, constructivist learning theory

\section{Introduction}

The information exchange in the setting of multi-media and Internet has caused an unprecedented change in the history of the world. The communication of human beings has been expanded in temporal and spatial variation, which provides an effective way to improve foreign language education. Especially, a student has new way to construct his or her personal understanding of a text in the studying of Advanced English course. The application of Internet technology has brought not only advantages to Advanced English teaching, but also challenges to its traditional teaching mode.
\end{abstract}

\section{The Concept of Advanced English Teaching in the Setting of Multi-media and Internet}

The development and application of multi-media and Internet technology makes human beings' communication more vivid and concrete, which helps people from different cultures communicate easier. The traditional method, interpreting a text by translation based on grammar rules, could not meet the need of the information exchange any more. However, the cognitive and communicative approaches based on psycholinguistics and sociolinguistics have become more acceptable, which can follow the principle of students' studying English. These methods can cultivate the students' creative thinking and communicative competence. The cognitive method is based on the constructivist learning theory raised by J. Piaget, which emphasizes that learners are the main body of study. It holds that the act of knowing is the interaction between the individual and his or her external environment. The learners make good use of their past experience to interact with their external environment in order to construct their new knowledge [1]. Language study needs to get the information and knowledge through the way of listening and reading. More importantly, the communication between people can be realized through the way in which the input information must be processed and output in a real situation. To meet the need of this cognition and communication, the modern English teaching advocates that the students are the main body, who can construct their knowledge with the help of a teacher and other external environment(e.g. teacher, classmates and media). The concept of Advanced English teaching in the setting of multi-media and Internet values the principle position of students, in which their external environment consists of teacher, classmates and media. A teacher plays the role as an organizer, a guider, an evaluator and an urger. The cognitive subject (students) needs to improve the way constantly to construct his or her knowledge in the process of dealing with the information he or she obtains. Hence, the modern Advanced English teaching in the setting of multi-media and Internet centres around the students. According to the requirement of Teaching Syllabus of English Major in University, the aim of the Advanced English teaching is not only to cultivate students to read, write effectively, but also to have a good command of rhetorical devices and comprehensive skills, including how to help students obtain knowledge by themselves, analyse the problems they encounter, and apply the knowledge they have in a creative way, which can develop their ability to communicate in English [2].

\section{The Advantages of Advanced English Teaching in the Setting of Multi-media and Internet}

Advanced English is one of the main courses for senior students in English major. Its reading materials are from the famous works, involving politics, economy, society, language, literature, education and philosophy, which styles are in variety and rhetorical devices are used widely. However, the class hours are quite limited. All these have been besetting both the teacher and the students. In order to finish teaching task, a teacher has to employ the cramming method with chalks and text book in the traditional teaching, which fags out both the teacher and the students, but achieves little effect in helping students study.

The foreign language education assisted by information technology are characterized by digitalization, multimedia, Internet and intelligence, which are very helpful in developing individual cognition, supporting contextual teaching and cooperative learning. The technology helps Advanced English teaching free from the traditional mode [3]. A teacher can make good use of context, cooperation and dialogue to motivate the students' interests and creative thinking to construct their new knowledge. The boring teaching and 
learning becomes interesting and vivid in this setting, and even the heavy task seems to be light-hearted. The development and application of multi-media and Internet technology bring about advantages for Advanced English teaching.

\section{A. The increase of information in teaching and the visualization of knowledge}

The subjects of essays in Advanced English text books are extensive and the background knowledge of the essays is very rich. Many allusions are hidden between the lines, which cannot be interpreted in detail in traditional teaching because of the limited class hours and the teaching media. So, the students cannot have a good understanding even after they have studied the essays. In the setting of multi-media and Internet, a teacher may collect relevant material and design the teaching script in advance. In order to help students understand the essay better, a teacher may show the vivid teaching script in class or ask students to browse relevant websites. For example, "the first revolution", "one hundred days" and "Isaiah" mentioned in Inauguration Address of Book Two are some allusions related to American history and religion, which can be vividly visualized in the setting of multi-media and Internet. With these vivid pictures, video and audio, it is easy for students to learn American history, culture and religion. They could have a better understanding on the American society and the foreign policy of the U.S. during the days of the Cold War. A lot of information released by the teaching script could be unfolded before the class very quickly. Without more interpretation, the students could read between the lines easier. However, this could not be realized in the traditional teaching because of the limitation of class hours and teaching media. Although the time for one class is not increased, the more information involved in the essay could be released, which is much more than that in the traditional teaching. Especially, the way to release information, such as text, pictures, video and audio, becomes more vivid and concrete. This could motivate the students' interest and enthusiasm to construct their new knowledge, and also make them understand what they learn easily.

\section{B. The extension of class and the variation of teaching method}

The essays in Advanced English text books not only cover different subjects, but also are very long. A teacher would ask students to preview the text with some questions. But it is not easy for students to get the related material to make preparation. In the setting of multi-media and Internet, a teacher could make full use of the resources to design his or her teaching script or ask the students to browse some relevant websites, which can urge them to explore what they are interested. What's more, a teacher could upload the assignment he or she designs through qq group. Also, the students may discuss with their teacher and classmates about the study material in this qq group, from which the teacher could know how his or her students construct their new knowledge. The development and application of multi-media and Internet extends the class space. The study could be extended into qq group, in which the teaching scripts could be unfolded and the interaction between the students and the teacher could be done. The space of the class could be not only extended, but also the teaching method could be varied. The teaching could set free from time and space, which can meet the need of modern Advanced English teaching.

\section{The more interaction between teacher and students}

The class hours of Advanced English course compared to its rich content are quite limited. The traditional teaching has to use the cramming method in order to save time. So there is little interaction between students and their teacher. In the setting of multi-media and Internet, the teaching script designed by a teacher in advance, which covers text, pictures, video and audio, can save the time which is often used for a teacher to write on the blackboard in traditional mode. The time saved in this setting could be used for a teacher to help students construct their new knowledge, cultivate them how to explore what they are studying and focus on the important and difficult contents. The interaction between the teacher and students could be extended from class to Internet. A teacher may establish qq group of his or her class with some chat software, by which the students' question can be answered in time and the teacher can find out the problems in students' study. In this way, the interaction between teacher and students, students and students, becomes more and more frequent. They may discuss about how they study the essay at any time if they like, which sometimes is more effective than that between the teacher and the students. The constructivist learning theory holds that language could not be acquired only through teaching. It can be only obtained through the way that the learner uses his or her past experience to interact with his or her external environment. Their past experience is quite similar. So, they tend to encounter more similar study problems while they construct their knowledge. The teacher can solve the problems they share in class and help them to improve. But the constructing process cannot be separated from the setting of multi-media and Internet [4].

\section{The center position of students in teaching}

The setting of multi-media and Internet is a necessary technology support to change students' position in teaching. In the traditional teaching mode, the cramming method has to be used in order to finish the task required by syllabus. The limitation of teaching media focuses on teacher-centered mode. In this mode, the students are passive in constructing their knowledge, which violates the cognitive law. It becomes possible for students to study actively in the setting of multimedia and Internet. The students become the center of the teaching. For instance, the text "Marrakech" in Book Two exposes the evil of colonialists by the vivid description of the poor and miserable life of working people in colony. The essay involves colonialism, African culture, religion and customs, about which the students know little. In traditional teaching, a teacher has to slide over this background knowledge because of lack of class time. However, in the setting of multi-media 
and Internet, this background knowledge could be visualized through multimedia courseware in a short time. A teacher can focus on how his or her students study rather than the text. $\mathrm{He}$ or she can interpret more about writing skills, especially, the rhetorical devices. In this setting, a teacher can center around the students and expects to know if the students have good command of the essay rather than if he or she can finish teaching task. A teacher becomes an organizer, a guider, an evaluator and an urger.

\section{The Challenges for Advanced English Teaching in the Setting of Multi-media and Internet}

The concept of students-centred teaching can be really realized in the setting of multi-media and Internet, which follows the cognitive law. The application of multi-media and Internet contributes a lot to improving Advanced English teaching. However, the challenges brought by multi-media and Internet should not be ignored.

\section{A. The challenge for teaching management}

The setting of multi-media and Internet relies on the modern equipments and the technology support, which needs a large sum of money to buy the equipments and provide technical maintenance. However, not all universities can provide a satisfying network environment. Without this environment, the new teaching in Advanced English course cannot be met. Hence, the first challenge is for teaching management.

\section{B. The challenge for the computer and Internet operation skills of teachers and students}

With multi-media and Internet, a teacher can design and make Advanced English teaching courseware. In order to help students better understand the allusions between the lines, a teacher may make full use of the high resources from websites to design the teaching multi-media courseware. In the setting of multi-media and Internet, the interaction can be extended from class to qq group, which requires that both teachers and students have sure operation skills. However, it is quite necessary for some elderly teachers and few students to improve their skills.

C. The challenge for the self-consciousness of students.

The subjects of essays in Advanced English course are in variety. A teacher often asks students to preview the text and upload some relevant files to qq group, which requires them to study before the computer consciously. However, some students tend to be indulged in other things rather than the study files. So, the autonomous learning in the setting of multimedia and Internet needs more consciousness [5]. Otherwise, the extension of teaching in the setting of Internet will be a mere formality.

\section{Conclusions}

The setting of multi-media and Internet in information era provides foreign language education, especially Advanced English teaching with a chance to reform, which is an effective way to finish the task required in teaching syllabus. The concept of students-centred teaching can be really carried out, and the students' cognition can be well recognized. The students will have better insight into society and life through reading. To cultivate them to use English become practical. The setting of multi-media Internet is the support of the new teaching mode in Advanced English course.

\section{References}

[1] J. Piaget, "The Principles of Genetic Epistemology," Commercial Press, 1997.

[2] "English Teaching Syllabus for English Major," Foreign Language Teaching and Research Press, 2004.

[3] Qi Wu, "The Research on Foreign Language Teaching under the Information Technology Environment," China Social Science Press, 2006.

[4] Yimin Wang, "On English Situational Teaching from a Constructivist Learning Theory," Foreign Language Teaching, 2003(2) pp.56-58.

[5] Jiangxin Hua, "Model Design of Autonomous Learning under Network Education Context," China Distance Education, 2002(2) pp.47-50. 